\title{
BMJ Open Burnout, well-being and defensive medical practice among obstetricians and gynaecologists in the UK: cross- sectional survey study
}

\author{
Tom Bourne, ${ }^{1,2}$ Harsha Shah, ${ }^{1}$ Nora Falconieri, ${ }^{2}$ Dirk Timmerman, ${ }^{2}$ \\ Christoph Lees, ${ }^{1,2}$ Alison Wright, ${ }^{3}$ Mary Ann Lumsden, ${ }^{4}$ Lesley Regan, ${ }^{5}$ \\ Ben Van Calster ${ }^{2,6}$
}

To cite: Bourne T, Shah H, Falconieri N, et al. Burnout, well-being and defensive medical practice among obstetricians and gynaecologists in the UK: cross-sectional survey study. BMJ Open 2019;9:e030968. doi:10.1136/ bmjopen-2019-030968

- Prepublication history and additional material for this paper are available online. To view these files, please visit the journal online (http://dx.doi. org/10.1136/bmjopen-2019030968).

Received 09 April 2019 Revised 06 October 2019 Accepted 10 0ctober 2019

Check for updates

(C) Author(s) (or their employer(s)) 2019. Re-use permitted under CC BY-NC. No commercial re-use. See rights and permissions. Published by BMJ.

For numbered affiliations see end of article.

Correspondence to Professor Tom Bourne; t.bourne@imperial.ac.uk

\section{ABSTRACT}

Objectives To determine the prevalence of burnout in doctors practising obstetrics and gynaecology, and assess the association with defensive medical practice and selfreported well-being.

Design Nationwide online cross-sectional survey study; December 2017-March 2018.

Setting Hospitals in the UK.

Participants 5661 practising obstetrics and gynaecology consultants, specialty and associate specialist doctors and trainees registered with the Royal College of Obstetricians and Gynaecologists.

Primary and secondary outcome

measures Prevalence of burnout using the Maslach Burnout Inventory and defensive medical practice (avoiding cases or procedures, overprescribing, overreferral) using a 12-item questionnaire. The odds ratios (OR) of burnout with defensive medical practice and selfreported well-being.

Results $3102 / 5661$ doctors (55\%) completed the survey. 3073/3102 (99\%) met the inclusion criteria (1462 consultants, 1357 trainees and 254 specialty and associate specialist doctors). 1116/3073 (36\%) doctors met the burnout criteria, with levels highest amongst trainees (580/1357 (43\%)). 258/1116 (23\%) doctors with burnout reported increased defensive practice compared with 142/1957 (7\%) without (adjusted OR 4.35, 95\% Cl 3.46 to 5.49). ORs of burnout with well-being items varied between 1.38 and 6.37 , and were highest for anxiety $(3.59,95 \% \mathrm{Cl} 3.07$ to 4.21$)$, depression $(4.05,95 \% \mathrm{Cl}$ 3.26 to 5.04$)$ and suicidal thoughts $(6.37,95 \% \mathrm{Cl} 95 \% \mathrm{Cl}$ 3.95 to 10.7). In multivariable logistic regression, being of younger age, white or 'other' ethnicity, and graduating with a medical degree from the UK or Ireland had the strongest associations with burnout.

Conclusions High levels of burnout were observed in obstetricians and gynaecologists and particularly among trainees. Burnout was associated with both increased defensive medical practice and worse doctor well-being. These findings have implications for the well-being and retention of doctors as well as the quality of patient care, and may help to inform the content of future interventions aimed at preventing burnout and improving patient safety.
Strengths and limitations of this study

- First nationwide survey in the UK which examines the prevalence of burnout as well as its relationship to defensive medical practice and self-reported well-being.

- This study includes a large number of doctors working in obstetrics and gynaecology and has a good response rate.

- Use of the Maslach Burnout Inventory, a widely available and validated tool for measuring burnout among doctors allows for comparison with other research in this field.

- The response rate of $54.8 \%$ is a limitation which introduces the possibility of selection bias; this must be considered when interpreting the findings.

\section{INTRODUCTION}

Doctor burnout and mental well-being is an important concern internationally ${ }^{1-5}$ because of the high reported prevalence ${ }^{6}$ and serious consequences for both staff and patients. ${ }^{7}$ Burnout syndrome, which is a response to prolonged exposure to occupational stress, is characterised by three dimensions: emotional exhaustion (EE), depersonalisation (DP) and reduced personal accomplishment (PA) ${ }^{8}$ International studies have shown that burnout is nearly twice as common among doctors compared with other healthcare workers. ${ }^{7} \mathrm{~A}$ recent survey by the General Medical Council reported that $24 \%$ of trainees and $21 \%$ of trainers from across the United Kingdom (UK) described 'feeling burnt out' based on self-reported symptoms. ${ }^{9}$ The consequences of burnout among doctors have been investigated primarily in the United States (USA) ${ }^{10}$ with relatively few large studies conducted in Europe $^{11-16}$ and Asia ${ }^{1718}$ to validate these findings internationally. These include a negative impact on health including higher rates of 
substance abuse, depression, suicide and a poorer quality of life. ${ }^{19}{ }^{20}$ Moreover, burnout in doctors has a significant impact on the productivity of healthcare organisations, intentions to leave medical practice and both the quality and safety of patient care. ${ }^{21-25}$ At present, it is unclear if these findings and the proposed interventions can be extrapolated to the UK due to a paucity of data on doctor burnout in this setting. ${ }^{26} 27$

Evidence from studies in Europe ${ }^{1528}$ and the $\mathrm{USA}^{2}$ suggest that burnout may be experienced by up to half of doctors in obstetrics and gynaecology (O\&G) ${ }^{2930}$ and that the prevalence of burnout in O\&G is one of the highest of any specialty. This may be related to the high-acuity and rapid turnover of patients associated with O\&G. ${ }^{31}$ Burnout is also associated with increased job turnover and reduced workforce retention. ${ }^{32}{ }^{33}$ Furthermore, a key consequence of doctor burnout is the impact on patient care. A recent meta-analysis suggested that burnt out doctors are twice as likely to be involved in patient safety incidents and deliver a lower quality of patient care. ${ }^{34}$ This is a significant issue in $O \& G$, a specialty already associated with high levels of litigation, ${ }^{35}$ with obstetric claim settlements costing the National Health Service (NHS) over $£ 500$ million annually. ${ }^{36}$ These high litigation rates are partly attributable to the large number of safety incidents and complaints ${ }^{37} 38$ and a parallel culture of intolerance when errors are made. The overall impact of this 'complaints culture' on doctors is substantial. ${ }^{39} \mathrm{~A}$ UK-wide study on the impact of complaints on doctor welfare demonstrated that they are associated with an increased risk of depression, anxiety and suicidal ideation as well as increased defensive practice. ${ }^{40-42}$ Defensive medical practice (DMP) is defined as a doctor's deviation from standard practice in response to complaints or criticism ${ }^{43}$ which can potentially harm patients as a result of either overinvestigation and treatment or because clinicians avoid involvement in difficult cases. ${ }^{35} \mathrm{~A}$ small study of DMP among UK doctors demonstrated that $26.4 \%$ of $\mathrm{O} \& \mathrm{G}$ doctors report practising some form of defensive medicine. ${ }^{3543}$ Although the overall effect and cost of the practice of defensive medicine has not been established in the UK, it is thought to represent a highly significant strain on healthcare resources and in the USA, it is estimated to cost $\$ 46$ billion annually. ${ }^{44}$

There has been great focus by the UK government through initiatives such as 'The Maternal and Neonatal Health Safety Collaborative ${ }^{45}$ to implement strategies which aim to improve maternity safety and outcomes. A facet of this work involves 'understanding the culture' of the O\&G workforce ${ }^{45}$ However, to our knowledge, there is currently no quantitative data relating to burnout among doctors working in O\&G in the UK to inform policy and potential interventions in relation to NHS workforce sustainability ${ }^{46}$ as well as any impacts on the quality of patient care. ${ }^{6}$ Thus, there is a clear need to identify the prevalence and factors associated with burnout among doctors in O\&G. We conducted a nationwide cross-sectional survey study to assess burnout, DMP and associated personal and work factors in $\mathrm{O} \& \mathrm{G}$ doctors in the UK. The aims were firstly to ascertain the prevalence of burnout in the cohort, secondly to determine the levels of DMP and doctor well-being and explore their relationship with burnout. Finally, we aimed to explore the relationships between age, gender, ethnicity, doctor seniority, and both burnout and DMP.

\section{METHODS}

All consultants (equivalent to an attending physician in the USA), specialty and associate specialist (SAS) doctors (doctors who have completed specialist training but do not have a staff position) and trainees (equivalent to a resident or fellow in the USA) working in O\&G in the UK and registered with the Royal College of Obstetricians and Gynaecologists (RCOG) were invited to participate in this study between December 2017 and March 2018. Registration with the RCOG is mandatory for all obstetricians and gynaecologists practising in the UK. Doctors were sent an email containing information describing the study and a link to an encrypted online questionnaire. We made it clear to the participants in the invitation email that their participation was voluntary and that responses would be both anonymous and untraceable. Informed consent was implied on return of the survey. Unique surveys were created for each of the grades described and sent as part of the annual RCOG Workforce and Welfare survey that collects data about doctors' clinical practice and working patterns. During the survey period, four reminders were sent out. All actively practising doctors were included as well as doctors who were on sick leave, maternity leave or suspended from practice. Exclusion criteria included doctors who are fully retired, on a career break, in between jobs, not working in the UK at the time of the survey or those who are currently not employed.

\section{Survey}

We used a cross-sectional survey design with three participant groups: consultants, SAS doctors and trainees. We estimate that the time taken to complete the questionnaire was $20 \mathrm{~min}$.

All participants were asked to provide information on demographic variables, including age, gender, ethnicity (Office of National Statistics classification ${ }^{47}$ ), relationship status and if they have children. In addition, they were asked about some job and organisational factors such as rota design and career or retirement plans which were tailored to the participant group. These parameters were chosen based on previous studies suggesting that they have an association with burnout. ${ }^{48}$ The main outcomes - the Maslach Burnout Inventory Human Services Survey for Medical Personnel (MBI) ${ }^{49}$ DMP questionnaire and questions concerning well-being were the same for all groups. A copy of the survey (excluding the copyrightrestricted MBI) can be found in online supplementary eMethods. 


\section{Main outcomes and measures}

\section{Symptoms of burnout}

We measured burnout using the MBI, ${ }^{49}$ a validated 22-item tool to identify and characterise burnout. The MBI has three subscales to evaluate the three domains of burnout: emotional exhaustion (EE), depersonalisation (DP) and low personal accomplishment (PA). As in previous studies and according to convention, ${ }^{10} 4849$ burnout was defined as high EE (scores of 27 or greater; possible score range from 0 to 54) and/or high DP (scores of 10 or greater; possible score range from 0 to 30 ) as opposed to a total score. The PA score was also measured with low PA defined as scores of 33 or lower (possible score range from 0 to 48 ) but this was not used as a criterion for burnout in line with previous published work on the subject. ${ }^{48}$

\section{Defensive medical practice}

DMP was assessed using a 12-item questionnaire which has previously been developed and described. ${ }^{40}{ }^{42}$ Items are measured on a 5-point Likert scale (ranging from never to often). Nine items quantify 'hedging' behaviour, which is when doctors are overcautious, leading to overprescribing or overinvestigation. Three items quantify 'avoidance' behaviour which includes not taking on complicated patients and avoiding certain procedures or more difficult cases. We confirm this factor structure in online supplementary eMethods. Consistent with previous work, we defined elevated hedging behaviour as a score of 13 or more (possible score range from 0 to 36), and elevated avoidance behaviour as a score of 5 or more (possible score range from 0 to 12 ). ${ }^{40}$ We defined any DMP as having elevated levels of avoidance and/or hedging.

\section{Doctor well-being}

Doctors were asked to self-report on the presence or absence (yes or no) of a variety of common medical symptoms and conditions, including cardiovascular problems, gastrointestinal problems, headaches, minor colds, recurring respiratory infections, depression, anxiety, anger and irritability, suicidal thoughts, sleep problems, relationship problems and alcohol or drug misuse.

\section{Statistical analyses}

Spearman correlations between the MBI and DMP subscales and DMP were calculated. In order to investigate the association between burnout, DMP and well-being, we calculated odds ratios (ORs) based on univariable logistic regression with Firth bias correction.

Multivariable logistic regression with Firth bias correction was used to investigate the association between demographic variables and burnout, with results reported as adjusted ORs and visualised with a nomogram. The predictors of burnout in this analysis were age, gender, ethnicity, grade, having children, current relationship, medical degree (MD) origin (UK or Ireland vs other) and work status (full time vs less than full time). A similar multivariable analysis was performed with DMP as the dependent variable. For this model, the same predictors were used, with burnout added as an additional predictor.

For the logistic regression analyses, missing values were singly imputed using the method of fully conditional specification based on the above-mentioned list of predictors, the MBI subscales (as numerical scores) and the DMP subscales (as numerical scores).

R V.3.5.0 was used for the statistical analysis.

\section{Patient and public involvement}

This research was designed and conducted without patient and public involvement.

\section{RESULTS \\ Respondent characteristics}

The survey was sent to a total of 5661 doctors. The overall response rate was $54.8 \%(3102 / 5661)$. We received questionnaires from 1481 consultants $(53 \%$ of 2786 consultants contacted), 1364 trainees (57\% of 2375 trainees contacted) and 257 SAS doctors ( $51 \%$ of 500 contacted). Of these, 1462 consultants, 1357 trainees and 254 SAS doctors were actively practising and included in the analysis. The mean age was 50 years for consultants, 33 years for trainees and 47 years for SAS doctors (table 1). The majority of doctors were female ( $58 \%$ of the consultants, $80 \%$ of the trainees, $68 \%$ of the SAS doctors). Consultants $(57 \%)$ and trainees $(64 \%)$ were predominantly white, whereas SAS doctors were most often of Asian ethnicity (42\%). Descriptive statistics by demographic variables are presented in table 2 . Information on missing data is presented in online supplementary eTable 1.

We were unable to reliably check if our sample for all doctors was representative of the entire population to whom the study survey was sent with regards to age, gender and ethnicity as the RCOG do not a hold a centralised database of these variables for all doctors against which to compare our data. However, the RCOG sent a different survey (Training Evaluation Form; TEF) to 1956 trainees in January 2018 which was responded to by 1754 trainees $(89.7 \%$ ) (online supplementary eTable 2). ${ }^{50}$ When comparing our data to this survey, we found that our trainee sample was comparable in terms of gender $(79.1 \%$ females in the TEF database compared with $79.8 \%$ in our cohort). Furthermore, our study population had similar numbers of trainees in the 20-29 and $30-39$ age ranges $(28.3 \%$ and $62.3 \%$, respectively, in the TEF database compared with $24.8 \%$ and $66.1 \%$, respectively, in our database). Our trainee cohort consisted of more doctors in the $40-59$ age range $(9.1 \%$ compared with $6.1 \%$ in the TEF database) which may be accounted for by missing data in the TEF database. In terms of ethnicity, our sample was also comparable for all groups.

\section{Burnout}

Regarding the MBI, the percentage of participants meeting the criteria for burnout was $36 \%$ overall (1116/3073; $95 \%$ CI $35 \%$ to $38 \%$ ); $31 \%$ for consultants (460/1462; 


\begin{tabular}{|c|c|c|c|}
\hline & $\begin{array}{l}\text { Consultants } \\
n=1481\end{array}$ & $\begin{array}{l}\text { SAS } \\
\mathrm{n}=257\end{array}$ & $\begin{array}{l}\text { Trainees } \\
n=1364\end{array}$ \\
\hline Actively practising & $1462(99 \%)$ & 254 (99\%) & $1357(99 \%)$ \\
\hline \multicolumn{4}{|l|}{ If actively practising* } \\
\hline Age, mean (range) & $50(33-73)$ & $47(27-74)$ & $33(25-58)$ \\
\hline Female & $831(58 \%)$ & $171(68 \%)$ & $1067(80 \%)$ \\
\hline \multicolumn{4}{|l|}{ Ethnicity } \\
\hline White & $831(57 \%)$ & 79 (31\%) & $857(64 \%)$ \\
\hline Asian & $438(30 \%)$ & $106(42 \%)$ & $288(21 \%)$ \\
\hline Black & $88(6 \%)$ & $23(9 \%)$ & $90(7 \%)$ \\
\hline Mixed & $58(4 \%)$ & $26(10 \%)$ & $88(7 \%)$ \\
\hline Other & $37(3 \%)$ & $19(8 \%)$ & $26(2 \%)$ \\
\hline Children & 1267 (87\%) & $198(78 \%)$ & $585(43 \%)$ \\
\hline Relationship & $1269(87 \%)$ & $216(85 \%)$ & $979(72 \%)$ \\
\hline Qualified in UK/Ireland & $865(59 \%)$ & $42(17 \%)$ & $1089(80 \%)$ \\
\hline Full time & $1276(87 \%)$ & $211(83 \%)$ & $1064(79 \%)$ \\
\hline \multicolumn{4}{|c|}{ Subspecialty (consultants) } \\
\hline None & $1278(87 \%)$ & $\mathrm{N} / \mathrm{A}$ & $\mathrm{N} / \mathrm{A}$ \\
\hline $\begin{array}{l}\text { Maternal/fetal } \\
\text { medicine }\end{array}$ & $56(4 \%)$ & $\mathrm{N} / \mathrm{A}$ & N/A \\
\hline $\begin{array}{l}\text { Sexual/reproductive } \\
\text { health }\end{array}$ & $34(2 \%)$ & $\mathrm{N} / \mathrm{A}$ & N/A \\
\hline $\begin{array}{l}\text { Gynaecological } \\
\text { oncology }\end{array}$ & $33(2 \%)$ & $\mathrm{N} / \mathrm{A}$ & N/A \\
\hline $\begin{array}{l}\text { Reproductive } \\
\text { medicine }\end{array}$ & $33(2 \%)$ & $\mathrm{N} / \mathrm{A}$ & N/A \\
\hline Urogynaecology & $28(2 \%)$ & $\mathrm{N} / \mathrm{A}$ & N/A \\
\hline \multicolumn{4}{|c|}{ Maslach Burnout Inventory } \\
\hline \multicolumn{4}{|l|}{ Emotional exhaustion } \\
\hline Mean & $19.9(0-54)$ & $18.7(0-53)$ & $21.9(0-54)$ \\
\hline High† (\%) & $411(28 \%)$ & $65(26 \%)$ & $440(32 \%)$ \\
\hline \multicolumn{4}{|l|}{ Depersonalisation } \\
\hline Mean & $4.5(0-29)$ & $4.5(0-30)$ & $7.0(0-29)$ \\
\hline High $\ddagger(\%)$ & $178(12 \%)$ & $33(13 \%)$ & $394(29 \%)$ \\
\hline \multicolumn{4}{|c|}{ Personal accomplishment } \\
\hline Mean & $37.2(0-48)$ & $35.3(4-48)$ & $34.6(0-48)$ \\
\hline Low§ (\%) & $382(26 \%)$ & $95(37 \%)$ & $530(39 \%)$ \\
\hline Burnout $\bigoplus$ & $460(31 \%)$ & $76(30 \%)$ & $580(43 \%)$ \\
\hline \multicolumn{4}{|c|}{ Defensive medical practice } \\
\hline \multicolumn{4}{|l|}{ Avoidance } \\
\hline Mean & $1.4(0-12)$ & $1.1(0-12)$ & $0.9(0-10)$ \\
\hline Elevated $^{* *}(\%)$ & $125(9 \%)$ & $13(5 \%)$ & $58(4 \%)$ \\
\hline \multicolumn{4}{|l|}{ Hedging } \\
\hline Mean & $5.2(0-36)$ & $2.8(0-36)$ & $4.6(0-36)$ \\
\hline Elevated†† (\%) & $164(11 \%)$ & $11(4 \%)$ & $114(8 \%)$ \\
\hline $\begin{array}{l}\text { Any defensive } \\
\text { medical practice } \ddagger \ddagger\end{array}$ & $231(16 \%)$ & $20(8 \%)$ & $149(11 \%)$ \\
\hline
\end{tabular}

Continued
Table 1 Continued

$\begin{array}{lll}\text { Consultants } & \text { SAS } & \text { Trainees } \\ n=1481 & n=257 & n=1364\end{array}$

${ }^{*}$ Results for each variable are based on available data, that is, excluding participants with a missing value. Gender has the most missing values, $41 / 3073$ (1.3\%). Missing values for all variables are reported in online supplementary eTable1.

$\dagger$ Scores of $\geq 27$ (range 0-54) are considered high and indicate burnout in accordance with the Maslach Burnout Inventory. $\ddagger$ Scores of $\geq 10$ (range $0-30$ ) are considered high and indicate burnout in accordance with the Maslach Burnout Inventory. $\S$ The score range is $0-48$; scores $\leq 33$ are defined as low personal accomplishment.

ПPositive for burnout if emotional exhaustion and/or depersonalisation scores high (as defined) in accordance with the Maslach Burnout Inventory.

${ }^{* *}$ Scores of $\geq 13$ (range $0-36$ ) are considered elevated and indicate avoidance behaviour.

††Scores of $\geq 5$ (range 0-12) are considered elevated and indicate hedging behaviour.

$\ddagger \ddagger$ Defined as elevated levels of avoidance and/or hedging behaviour.

SAS, Specialty and Associate Specialist Doctors.

$95 \%$ CI $29 \%$ to $34 \%)$, $43 \%$ for trainees $(580 / 1364$; $95 \%$ CI $40 \%$ to $45 \%)$, and $30 \%$ for SAS doctors $(76 / 254$; $95 \%$ CI $25 \%$ to $36 \%$ ) (table 1 and online supplementary eFigure 1). Between $26 \%$ and $32 \%$ met the criteria for high EE, between $12 \%$ and $29 \%$ met the criteria for high DP and between $26 \%$ and $39 \%$ met the criteria for low PA. The EE and DP scales had a Spearman correlation of 0.57 , whereas both subscales correlated negatively with PA ( -0.30 and -0.34 , respectively) (online supplementary eTable 3).

\section{Defensive medical practice}

Increased DMP, according to our criteria, was observed in $13 \%$ overall $(400 / 3073) ; 16 \%$ of consultants $(231 / 1462)$, $11 \%$ of trainees $(149 / 1364)$ and $8 \%$ of SAS doctors $(20 / 254)$. Between $4 \%$ and $9 \%$ met our criteria for increased avoidance, and between $4 \%$ and $11 \%$ met our criteria for increased hedging. These subscales had a Spearman correlation of 0.41 (online supplementary eTable 3 and eFigure 1).

Of all participants who met the criteria for burnout, $23 \%$ met the criteria for increased DMP (258/1116) (table 3). Of participants who did not meet the criteria for burnout, 7\% reported increased DMP (142/1957). The crude OR was 3.84 (95\% CI 3.08 to 4.79 ). The relationship was similar for all categories of doctors, and was observed for avoidance as well as hedging behaviour (table 3 and online supplementary eTable 4 ).

\section{Doctor well-being}

Doctors with burnout had a higher prevalence of selfreported medical illness (table 4). Highest ORs were observed for suicidal thoughts $(6.37,95 \%$ CI 3.95 to 10.7$)$, depression $(4.05$, 95\% CI 3.26 to 5.04), anxiety (3.59, $95 \%$ CI 3.07 to 4.21 ), anger/irritability (3.51, 95\% CI 3.00 to 4.10$)$, sleep problems or insomnia $(3.15,95 \%$ CI 2.70 to 3.67$)$ and substance misuse (2.57, $95 \%$ CI 1.71 to 3.89$)$; 
Table 2 Descriptive statistics of burnout and defensive medical practice stratified by demographic variables

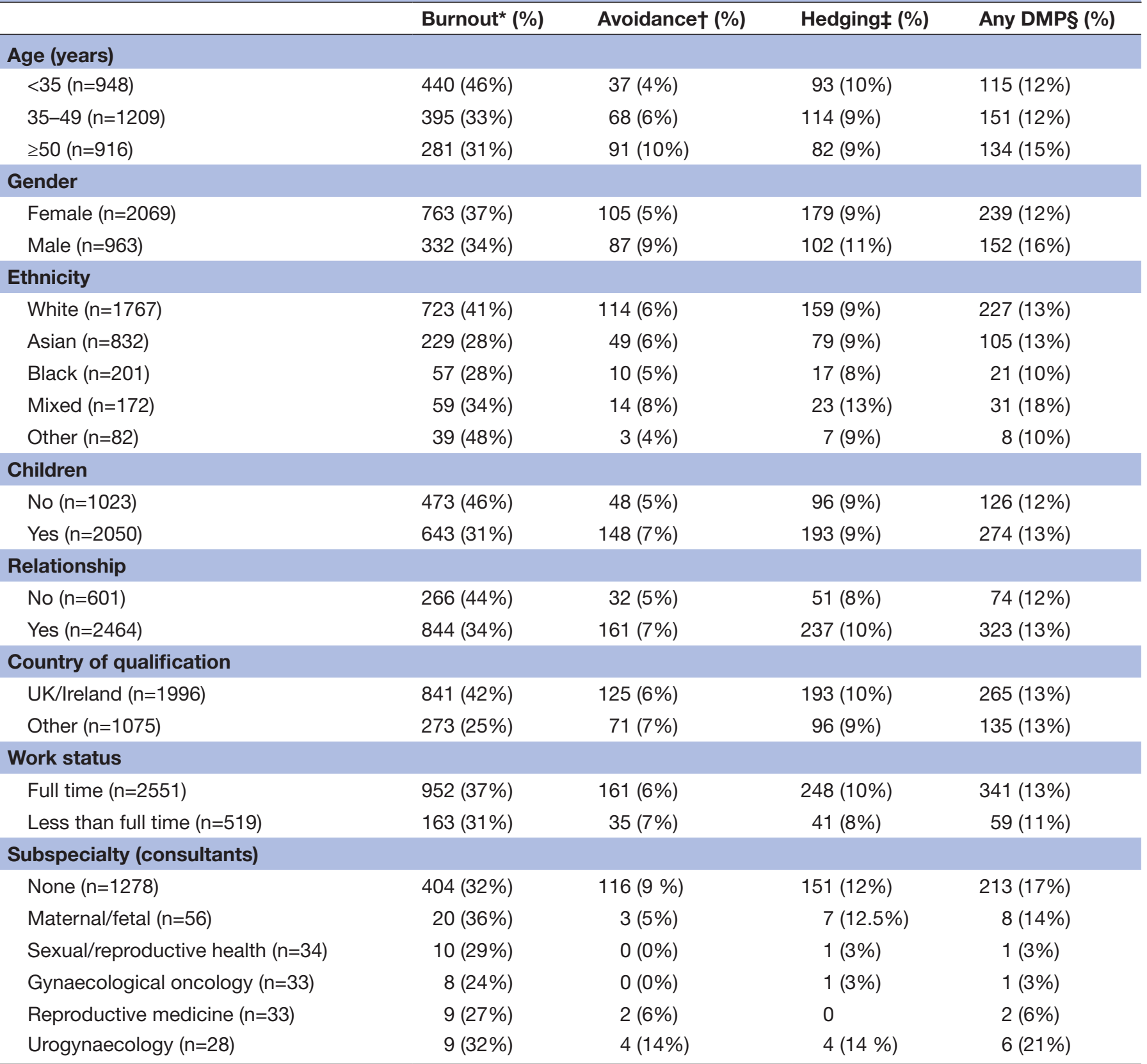

*Positive for burnout if emotional exhaustion score $\geq 27$ (range 0-54) and/or depersonalisation score $\geq 10$ (range 0-30) in accordance with the Maslach Burnout Inventory.

†Defined as avoidance score of $\geq 13$ (range 0-36).

‡Defined as hedging score of $\geq 5$ (range $0-12$ ).

$\S$ Defined as presence of avoidance and/or hedging (as defined).

DMP, Defensive Medical Practice.

$13.5 \%(\mathrm{n}=416)$ of all doctors reported depression, but this was $7.4 \%$ for doctors without burnout and $24.4 \%$ for doctors with burnout. Furthermore, 2.9\% ( $\mathrm{n}=90)$ of all doctors reported suicidal thoughts, $1.0 \%$ among doctors without and $6.3 \%$ among doctors with burnout. The OR was lowest for cardiovascular problems (1.38, 95\% CI 1.07 to 1.78$)$.

\section{Risk factors and correlates}

Results of the multivariable models are presented in table 5 and online supplementary eFigure 2 . Age, ethnicity and origin of MD degree were most strongly related to burnout. The older the doctor, the lower the reported level of burnout (adjusted OR per 5 years $0.92,95 \%$ CI 0.87 to 0.98 ) and doctors of white and 'other' ethnicity reported higher levels of burnout $(41 \%$ and $48 \%$, respectively) than doctors of other ethnicities (28\% to $34 \%$ ). Doctors with an MD from the UK or Ireland also reported higher levels of burnout ( $42 \%$ vs $25 \%$, adjusted OR 1.74, $95 \%$ CI 1.41 to 2.16 ). 
Table 3 Descriptive statistics of defensive practice by burnout status

\begin{tabular}{|c|c|c|c|c|c|}
\hline \multirow{2}{*}{$\begin{array}{l}\text { Doctor category } \\
\text { Burnout status§ }\end{array}$} & \multicolumn{2}{|l|}{ Avoidance* } & \multicolumn{2}{|l|}{ Hedgingt } & \multirow{2}{*}{$\begin{array}{l}\text { Any DMP } \\
\%\end{array}$} \\
\hline & Mean score & $\%$ elevated & Mean score & $\%$ elevated & \\
\hline \multicolumn{6}{|l|}{ Consultant } \\
\hline Burnout $(n=460)$ & 2.14 & $72(16 \%)$ & 7.79 & 97 (21\%) & $130(28 \%)$ \\
\hline \multicolumn{6}{|l|}{ SAS } \\
\hline Burnout $(n=76)$ & 1.92 & $10(13 \%)$ & 5.34 & $9(12 \%)$ & $15(20 \%)$ \\
\hline \multicolumn{6}{|l|}{ Trainees } \\
\hline No burnout $(n=777)$ & 0.59 & $15(2 \%)$ & 3.30 & $25(3 \%)$ & $36(5 \%)$ \\
\hline Burnout $(n=580)$ & 1.38 & $43(7 \%)$ & 6.46 & $89(15 \%)$ & $113(19 \%)$ \\
\hline \multicolumn{6}{|l|}{ All doctors } \\
\hline
\end{tabular}

${ }^{*}$ Scores of $\geq 13$ (range $0-36$ ) are considered elevated and indicate avoidance behaviour.

†Scores of $\geq 5$ (range $0-12$ ) are considered elevated and indicate hedging behaviour.

$\ddagger$ Defined as elevated levels of avoidance and/or hedging behaviour.

§Burnout defined as an emotional exhaustion score $\geq 27$ (range 0-54) and/or depersonalisation score $\geq 10$ (range 0-30) in accordance with the Maslach Burnout Inventory.

ПORs are based on univariable logistic regression with Firth bias correction.

DMP, Defensive Medical Practice; SAS, Specialty and Associate Specialist Doctors.

Regarding any DMP, burnout was the strongest predictor, followed by age, type of doctor and ethnicity. The adjusted OR of burnout to predict increased DMP was 4.35 (95\% CI 3.46 to 5.49). Consultants, doctors of mixed ethnicity and to a lesser extent older doctors reported the highest levels of DMP.

\section{DISCUSSION}

In this large nationwide study, we have shown that just under half of trainees and a third of consultants and SAS doctors working in O\&G in the UK suffer from burnout using the MBI scoring system. Furthermore, our data suggests that burnout is associated with higher levels of DMP, and with poorer mental and physical well-being.

The overall prevalence of burnout in this study is consistent with smaller international studies conducted within O\&G ${ }^{28} 291$ but lower than reported in the USA. ${ }^{25253}$ This may be explained by differences in the way burnout has been measured, the small number of subjects included in some studies, differences in healthcare systems as well as medical training, and the hours of work in the UK which are restricted by the European Working Time Directive. A lack of personal accomplishment and emotional exhaustion were the most commonly endorsed subscales, followed by depersonalisation. The particularly high levels of burnout among younger doctors, of whom the majority are trainees, may provide insights into a recent RCOG national training and workforce report. ${ }^{54}$ In this, nine out of ten O\&G trainees reported feeling low in mood, depressed or anxious since starting specialty training. ${ }^{54} \mathrm{In}$ keeping with this finding, and with a number of American studies, ${ }^{485}$ our data indicate that burnout is associated with a negative impact on doctor well-being and is strongly associated with depression, anxiety and suicidal thoughts.

Our study reported a particularly strong relationship between burnout and suicidal thoughts; worryingly, suicidal ideation has been shown to be strongly associated with actual suicide attempts and death. ${ }^{56}$ Furthermore, suicide rates in doctors are known to be much higher than for the general population. ${ }^{57}$ A study of surgeons in the $\mathrm{USA}^{58}$ found the prevalence of suicidal ideation in this group to be 6.3\%; although this is higher than the prevalence in this study (2.9\%), we found the association between burnout and suicidal ideation to be higher (OR, 6.37 vs $1.91^{58}$ ) in our cohort. This may reflect a vulnerability among doctors working in O\&G compared with other specialties $^{28}{ }^{29}$ or the differences in healthcare services and culture internationally.

Studies in the USA have indicated an association between burnout and increased workforce turnover ${ }^{59}$ which has both financial implications and an impact on healthcare organisation productivity. The RCOG national workforce report ${ }^{54}$ has reported that three quarters of trainees have considered leaving O\&G practice. In our study, as well as the highest prevalence of burnout among trainees, almost a fifth of trainees reported depression and over a third reported anxiety. These symptoms were markedly more prevalent in the cohort with burnout, and depression has been shown to be independently associated with an increased self-reported 
Table 4 Descriptive statistics of self-reported well-being, and ORs (with 95\% Cls) with burnout

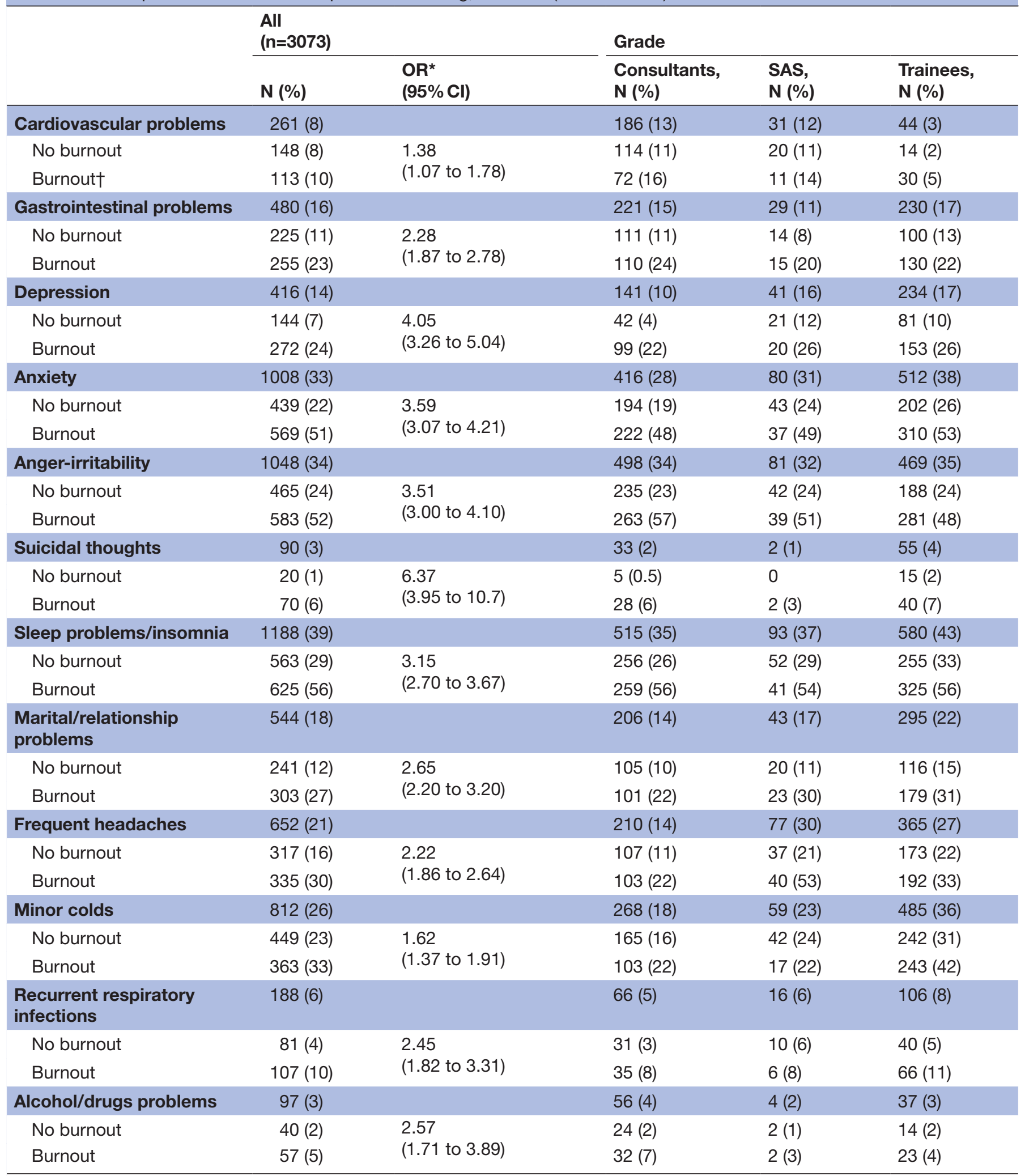

*ORs based on univariable Firth corrected logistic regression of well-being item vs burnout with stratification for group (consultant, SAS, trainee).

†Burnout defined as an emotional exhaustion score $\geq 27$ (range 0-54) and/or depersonalisation score $\geq 10$ (range $0-30$ ) in accordance with the Maslach Burnout Inventory.

SAS, Specialty and Associate Specialist Doctors. 
Table 5 Univariable and multivariable logistic regression results (using Firth bias correction)

\begin{tabular}{|c|c|c|c|c|}
\hline \multirow[b]{2}{*}{ Predictor variable } & \multicolumn{2}{|l|}{ Burnout* } & \multicolumn{2}{|l|}{ Any DMP† } \\
\hline & Crude OR & Adjusted OR & Crude OR & Adjusted OR \\
\hline \multicolumn{5}{|l|}{ Grade (vs consultants) } \\
\hline SAS & $\begin{array}{l}0.93 \\
(0.70 ; 1.24)\end{array}$ & $\begin{array}{l}1.14 \\
(0.83 ; 1.55)\end{array}$ & $\begin{array}{l}0.47 \\
(0.28 ; 0.73)\end{array}$ & $\begin{array}{l}0.40 \\
(0.23 ; 0.65)\end{array}$ \\
\hline Trainees & $\begin{array}{l}1.63 \\
(1.39 ; 1.90)\end{array}$ & $\begin{array}{l}1.00 \\
(0.77 ; 1.31)\end{array}$ & $\begin{array}{l}0.66 \\
(0.53 ; 0.82)\end{array}$ & $\begin{array}{l}0.47 \\
(0.32 ; 0.70)\end{array}$ \\
\hline Age (per 5 years) & $\begin{array}{l}0.87 \\
(0.84 ; 0.90)\end{array}$ & $\begin{array}{l}0.92 \\
(0.87 ; 0.98)\end{array}$ & $\begin{array}{l}1.04 \\
(0.99 ; 1.09)\end{array}$ & $\begin{array}{l}0.93 \\
(0.85 ; 1.02)\end{array}$ \\
\hline Female (vs male) & $\begin{array}{l}1.12 \\
(0.95 ; 1.31)\end{array}$ & $\begin{array}{l}0.97 \\
(0.81 ; 1.16)\end{array}$ & $\begin{array}{l}0.70 \\
(0.56 ; 0.87)\end{array}$ & $\begin{array}{l}0.70 \\
(0.55 ; 0.89)\end{array}$ \\
\hline \multicolumn{5}{|l|}{ Ethnicity (vs white) } \\
\hline Asian & $\begin{array}{l}0.54 \\
(0.45 ; 0.65)\end{array}$ & $\begin{array}{l}0.74 \\
(0.60 ; 0.91)\end{array}$ & $\begin{array}{l}0.98 \\
(0.77 ; 1.25)\end{array}$ & $\begin{array}{l}1.15 \\
(0.85 ; 1.54)\end{array}$ \\
\hline Black & $\begin{array}{l}0.57 \\
(0.41 ; 0.78)\end{array}$ & $\begin{array}{l}0.73 \\
(0.51 ; 1.02)\end{array}$ & $\begin{array}{l}0.79 \\
(0.48 ; 1.24)\end{array}$ & $\begin{array}{l}0.90 \\
(0.53 ; 1.47)\end{array}$ \\
\hline Mixed & $\begin{array}{l}0.75 \\
(0.54 ; 1.03)\end{array}$ & $\begin{array}{l}0.82 \\
(0.58 ; 1.15)\end{array}$ & $\begin{array}{l}1.53 \\
(1.01 ; 2.27)\end{array}$ & $\begin{array}{l}1.89 \\
(1.21 ; 2.89)\end{array}$ \\
\hline Other & $\begin{array}{l}1.37 \\
(0.88 ; 2.12)\end{array}$ & $\begin{array}{l}2.19 \\
(1.37 ; 3.52)\end{array}$ & $\begin{array}{l}0.84 \\
(0.40 ; 1.59)\end{array}$ & $\begin{array}{l}0.64 \\
(0.29 ; 1.30)\end{array}$ \\
\hline Children & $\begin{array}{l}0.53 \\
(0.46 ; 0.62)\end{array}$ & $\begin{array}{l}0.78 \\
(0.64 ; 0.97)\end{array}$ & $\begin{array}{l}1.10 \\
(0.88 ; 1.38)\end{array}$ & $\begin{array}{l}1.03 \\
(0.75 ; 1.41)\end{array}$ \\
\hline Current relationship & $\begin{array}{l}0.65 \\
(0.54 ; 0.78)\end{array}$ & $\begin{array}{l}0.87 \\
(0.70 ; 1.07)\end{array}$ & $\begin{array}{l}1.06 \\
(0.82 ; 1.40)\end{array}$ & $\begin{array}{l}1.07 \\
(0.79 ; 1.46)\end{array}$ \\
\hline $\begin{array}{l}\text { Medical Qualification } \\
\text { from UK/Ireland (vs } \\
\text { other country) }\end{array}$ & $\begin{array}{l}2.13 \\
(1.81 ; 2.51)\end{array}$ & $\begin{array}{l}1.74 \\
(1.41 ; 2.16)\end{array}$ & $\begin{array}{l}1.06 \\
(0.85 ; 1.33)\end{array}$ & $\begin{array}{l}0.84 \\
(0.63 ; 1.14)\end{array}$ \\
\hline $\begin{array}{l}\text { Full time (vs less than full } \\
\text { time) }\end{array}$ & $\begin{array}{l}1.30 \\
(1.06 ; 1.59)\end{array}$ & $\begin{array}{l}1.28 \\
(1.02 ; 1.62)\end{array}$ & $\begin{array}{l}1.19 \\
(0.90 ; 1.61)\end{array}$ & $\begin{array}{l}0.91 \\
(0.65 ; 1.27)\end{array}$ \\
\hline Burnout & & & $\begin{array}{l}3.84 \\
(3.08 ; 4.79)\end{array}$ & $\begin{array}{l}4.35 \\
(3.46 ; 5.49)\end{array}$ \\
\hline
\end{tabular}

*Burnout defined as an emotional exhaustion score $\geq 27$ (range 0-54) and/or depersonalisation score $\geq 10$ (range 0-30) in accordance with the Maslach Burnout Inventory.

†DMP defined as elevated levels of avoidance and/or hedging behaviour.

DMP, defensive medical practice; SAS, Specialty and Associate Specialist Doctors.

likelihood of leaving practice among surgeons. ${ }^{60}$ Better understanding the relationship between burnout, wellbeing and staff turnover intentions is of great importance to ensure retention of the workforce going forward. This knowledge will also help to inform the content of interventions aimed at identifying and preventing burnout, and improving the well-being and retention of doctors early in their careers. ${ }^{61}$ The majority of interventions proposed to date have been individual-focused strategies which include mindfulness,${ }^{62}$ personal coping strategies and exercise, ${ }^{63}$ or some combination of these. However, a recent metaanalysis of interventions to reduce doctor burnout found that organisation-directed interventions (such as reducing workload, changing rota/shift patterns or group sessions to enhance teamwork) had a more significant effect on reducing burnout than individual approaches alone. ${ }^{23}$ This highlights the importance of implementing organisational strategies $^{6465}$ along with continual assessment of burnout, to develop a healthy workplace environment to effectively tackle this problem. ${ }^{5}$

Our finding that burnout is associated with increased DMP supports the concern that doctor burnout impacts the quality of patient care. ${ }^{34}$ In 2010, Shanafelt et $a l^{19}$ showed that burnout is an independent predictor of self-reported perceived major medical errors. Our study shows that consultants with burnout are three times more likely to report both avoidance (avoiding cases or procedures) and hedging (overprescribing or over-referral) which may have significant and serious consequences on patient care. This may be because consultants are less 'protected' than trainees in terms of litigation as they take ultimate responsibility for a patient's care. Furthermore, due to their seniority, they are likely to have experienced more complaints or adverse events during their careers, which have been shown to be associated with DMP. ${ }^{42}$ The observation in our study that age is inversely associated 
with burnout is also in keeping with other studies. ${ }^{66}$ This may be explained by the fact that doctors who remain within the specialty are inherently more resilient, and that those more affected by burnout may be accounted for in the attrition rate from the specialty. ${ }^{67}$ It has also been suggested that the lower rate of burnout seen in more senior doctors is because they may have a better worklife balance and career. ${ }^{6768} \mathrm{~A}$ further noteworthy association in our cohort was that after controlling for other confounding variables, doctors from ethnic minorities were less likely to experience burnout. Similar findings have been reported in studies of trainees and medical students in the USA ${ }^{69-71}$; however, the reasons for this are unknown. It has been proposed that that these differences may be explained by differences in upbringing and life stressors, which may make doctors from ethnic minorities more resilient. ${ }^{69}$ Consistent with this, we found that doctors who graduated in the UK or Ireland are almost twice as likely to experience burnout.

Strengths and weaknesses of our study are important to consider in contrast with other research on the prevalence of burnout in doctors. A strength of the study is that it is a nationwide survey which includes a large number of doctors and is the first study to our knowledge that seeks to explore the relationship between burnout (using a validated tool, the MBI) and DMP. There were several limitations to the present study. First, although the overall response rate was only $54.8 \%$ which is a relatively high response rate for a survey study of this type, it still introduces the possibility of selection bias, which must be considered when interpreting the findings. We believe however that the response rate quoted is the minimum rate and is likely to under-report the response rate from practising clinicians (online supplementary eDiscussion). Second, it is plausible that individuals most affected by burnout may have avoided engaging with the survey and conversely those least impacted may not have seen its value which could bias the results. Third, we asked doctors to self-report on medical conditions including depression and anxiety and the questionnaire used to assess DMP, although used in previous studies, ${ }^{40-42}$ has not been formally validated. Finally, a limitation of a cross-sectional survey study is that it cannot take into account variability of symptoms over time, which may be influenced by other factors such as time of the year and other personal factors.

\section{CONCLUSIONS}

Our nationwide study reports high levels of burnout among obstetricians and gynaecologists in the UK, and that burnout is more prevalent in younger doctors who have trained in the UK. Furthermore, our data suggest that burnout is strongly associated with anxiety, depression, suicidal thoughts and substance misuse. This highlights the impact of burnout on the efficiency and sustainability of the O\&G medical workforce which confirms the need to regularly assess and mitigate burnout in doctors. We have also observed an association between burnout and
DMP, which has implications for the quality and safety of patient care being delivered as well as the well-being and retention of staff in the NHS. Ultimately, cultivating a greater understanding of doctor burnout and its implications has strategic importance for the sustainability of the NHS workforce and will add to the body of evidence required to improve productivity and patient safety outcomes more broadly across the UK.

\section{Author affiliations}

${ }^{1}$ Department of Obstetrics and Gynaecology, Queen Charlotte's and Chelsea Hospital, Imperial College London, London, UK

${ }^{2}$ Department of Development \& Regeneration, KU Leuven, Leuven, Belgium ${ }^{3}$ Department of Obstetrics and Gynaecology, Royal Free Hospital, London, UK ${ }^{4}$ Department of Obstetrics and Gynaecology, University of Glasgow, Glasgow, UK ${ }^{5}$ Department of Obstetrics and Gynaecology, St Mary's Hospital, Imperial College Healthcare NHS Trust, London, UK

${ }^{6}$ Department of Biomedical Data Sciences, Leiden University Medical Centre, Leiden, Netherlands

\section{Twitter Tom Bourne @proftombourne and Harsha Shah @harsha_shah86}

Acknowledgements Victoria Bytel contributed to conduct of the study and facilitated data collection.

Contributors TB had full access to all of the data in the study and takes responsibility for the integrity of the data and the accuracy of the data analysis. Concept and design: TB, CL, AW, LR. Acquisition, analysis and interpretation of data: TB, HS, NF, DT, CL, AW, MAL, LR, BVC. Drafting of the manuscript: TB, HS, BVC. Critical revision of the manuscript for important intellectual content: TB, HS, NF, DT, CL, AW, MAL, LR, BVC. Statistical analysis: NF, BVC. Obtained funding: TB. TB is the guarantor and attests that all listed authors meet authorship criteria and that no others meeting the criteria have been omitted.

Funding The Royal College of Obstetricians and Gynaecologists supported the costs of using the Maslach Burnout Inventory. The study received no additional funding.

Map disclaimer The funders had no role in the study design; collection, management, analysis and interpretation of the data; preparation, writing, review or approval of the manuscript; and decision to submit the manuscript for publication. All authors had full access to all of the data in the study, can take responsibility for the integrity of the data, and had final responsibility for the decision to submit for publication.

Competing interests None declared.

Patient consent for publication Not applicable

Ethics approval The survey was sent to doctors registered with the Royal College of Obstetricians and Gynaecologists via their email database. The Chair of the RCOG Ethics Committee (Vivienne Nathanson) reviewed the study proposal and confirmed that ethical approval was not required. This was due to the fact that the data collected about doctors was via an encrypted online questionnaire and participants were informed that their participation was voluntary and that responses would be both anonymous and untraceable. Informed consent was implied on return of the survey.

Provenance and peer review Not commissioned; externally peer reviewed.

Data availability statement № data are available.

Open access This is an open access article distributed in accordance with the Creative Commons Attribution Non Commercial (CC BY-NC 4.0) license, which permits others to distribute, remix, adapt, build upon this work non-commercially, and license their derivative works on different terms, provided the original work is properly cited, appropriate credit is given, any changes made indicated, and the use is non-commercial. See: http://creativecommons.org/licenses/by-nc/4.0/.

\section{REFERENCES}

1 Arigoni F, Bovier PA, Sappino AP. Trend of burnout among Swiss doctors. Swiss Med Wkly 2010;140:w13070.

2 Gabbe SG, Melville J, Mandel L, et al. Burnout in chairs of obstetrics and gynecology: diagnosis, treatment, and prevention. Am J Obstet Gynecol 2002;186:601-12. 
3 Wang Z, Xie Z, Dai J, et al. Physician burnout and its associated factors: a cross-sectional study in Shanghai. J Occup Health 2014;56:73-83.

4 Klein J, Grosse Frie K, Blum K, et al. Burnout and perceived quality of care among German clinicians in surgery. Int J Qual Health Care 2010;22:525-30.

5 Montgomery A, Panagopoulou E, Esmail A, et al. Burnout in healthcare: the case for organisational change. BMJ 2019;366.

6 Johnson J, Bu C, Panagioti M. Tackling burnout in UK trainee doctors is vital for a sustainable, safe, high quality NHS. BMJ 2018;362.

7 Shanafelt TD, Hasan O, Dyrbye LN, et al. Changes in burnout and satisfaction with work-life balance in physicians and the general us working population between 2011 and 2014. Mayo Clin Proc 2015;90:1600-13.

8 Maslach C, Schaufeli WB, Leiter MP. Job burnout. Annu Rev Psychol 2001;52:397-422.

9 General medical Council(GMC). National training surveys 2018: initia findings report, 2018. Available: https://www.gmc-uk.org/about/ what-we-do-and-why/data-and-research/national-training-surveysreports

10 Rotenstein LS, Torre M, Ramos MA, et al. Prevalence of burnout among physicians: a systematic review. JAMA 2018;320:1131-50.

11 Wurm W, Vogel K, Holl A, et al. Depression-Burnout overlap in physicians. PLoS One 2016;11:e0149913.

12 Vandenbroeck S, Van Gerven E, De Witte H, et al. Burnout in Belgian physicians and nurses. Occup Med 2017;67:546-54.

13 Pedersen AF, Sørensen JK, Bruun NH, et al. Risky alcohol use in Danish physicians: associated with alexithymia and burnout? Drug Alcohol Depend 2016;160:119-26.

14 Pantenburg B, Luppa M, König $\mathrm{H}-\mathrm{H}$, et al. Burnout among young physicians and its association with physicians' wishes to leave: results of a survey in Saxony, Germany. J Occup Med Toxicol 2016;11.

15 Ruitenburg MM, Frings-Dresen MHW, Sluiter JK. The prevalence of common mental disorders among hospital physicians and their association with self-reported work ability: a cross-sectional study. BMC Health Serv Res 2012;12:292-8.

16 Baas MAM, Scheepstra KWF, Stramrood CAI, et al. Work-Related adverse events leaving their mark: a cross-sectional study among Dutch gynecologists. BMC Psychiatry 2018;18:73.

17 Li H, Zuo M, Gelb AW, et al. Chinese Anesthesiologists have high burnout and low job satisfaction: a cross-sectional survey. Anesth Analg 2018;126:1004-12.

18 Wu H, Liu L, Wang Y, et al. Factors associated with burnout among Chinese hospital doctors: a cross-sectional study. BMC Public Health 2013;13:786.

19 Shanafelt TD, Balch CM, Bechamps G, et al. Burnout and medical errors among American surgeons. Ann Surg 2010;251:995-1000.

20 Shanafelt TD, Gradishar WJ, Kosty M, et al. Burnout and career satisfaction among US oncologists. JCO 2014;32:678-86.

21 Dewa CS, Loong D, Bonato S, et al. The relationship between physician burnout and quality of healthcare in terms of safety and acceptability: a systematic review. BMJ Open 2017;7:e015141.

22 Hall LH, Johnson J, Watt I, et al. Healthcare staff wellbeing, burnout, and patient safety: a systematic review. PLoS One 2016;11:e0159015.

23 Panagioti M, Panagopoulou E, Bower P, et al. Controlled interventions to reduce burnout in physicians: a systematic review and meta-analysis. JAMA Intern Med 2017;177:195-205.

24 Salyers MP, Bonfils KA, Luther L, et al. The relationship between professional burnout and quality and safety in healthcare: a metaanalysis. J Gen Intern Med 2017;32:475-82.

25 Hall LH, Johnson J, Heyhoe J, et al. Exploring the impact of primary care physician burnout and wellbeing on patient care: a focus group study. J Patient Saf;2017.

26 Rimmer A. Employers must tackle high level of burnout among trainees, says GMC. BMJ 2018;362.

27 Imo UO. Burnout and psychiatric morbidity among doctors in the UK: a systematic literature review of prevalence and associated factors. BJPsych Bull 2017;41:197-204.

28 Castelo-Branco C, Figueras F, Eixarch E, et al. Stress symptoms and burnout in obstetric and gynaecology residents. BJOG 2007;114:94-8.

29 Moradi Y, Baradaran HR, Yazdandoost M, et al. Prevalence of burnout in residents of obstetrics and gynecology: a systematic review and meta-analysis. Med J Islam Repub Iran 2015;29:235.

30 Dyrbye LN, Burke SE, Hardeman RR, et al. Association of clinical specialty with symptoms of burnout and career choice regret among US resident physicians. JAMA 2018;320:1114-30.
31 lorga M, Socolov V, Muraru D, et al. Factors influencing burnout syndrome in obstetrics and gynecology physicians. Biomed Res Int 2017;2017

32 Shanafelt T, Goh J, Sinsky C. The business case for investing in physician well-being. JAMA Intern Med 2017;177:1826-32.

33 Landon BE, Reschovsky JD, Pham HH, et al. Leaving medicine: the consequences of physician dissatisfaction. Med Care 2006;44:234-42.

34 Panagioti M, Geraghty K, Johnson J, et al. Association between physician burnout and patient safety, professionalism, and patient satisfaction: a systematic review and meta-analysis. JAMA Intern Med 2018:178:1317-30.

35 Studdert DM, Mello MM, Sage WM, et al. Defensive medicine among high-risk specialist physicians in a volatile malpractice environment. JAMA 2005;293:2609-17.

36 NHS Resolution. Annual report and accounts 2017/2018, 2018. Available: https://resolution.nhs.uk/annual-report-and-accounts/

37 Xu X, Siefert KA, Jacobson PD, et al. The effects of medical liability on obstetric care supply in Michigan. Am J Obstet Gynecol 2008;198:205.e1-205.e9.

38 Barbieri RL. Professional liability payments in obstetrics and gynecology. Obstet Gynecol 2006;107:578-81.

39 Zwecker P, Azoulay L, Abenhaim HA. Effect of fear of litigation on obstetric care: a nationwide analysis on obstetric practice. Am J Perinatol 2011;28:277-84.

40 Bourne T, Wynants L, Peters M, et al. The impact of complaints procedures on the welfare, health and clinical practise of 7926 doctors in the UK: a cross-sectional survey. BMJ Open 2015;5:e006687.

41 Bourne T, Vanderhaegen J, Vranken R, et al. Doctors' experiences and their perception of the most stressful aspects of complaints processes in the UK: an analysis of qualitative survey data. BMJ Open 2016;6:e011711.

42 Bourne T, De Cock B, Wynants L, et al. Doctors' perception of support and the processes involved in complaints investigations and how these relate to welfare and defensive practice: a cross-sectional survey of the UK physicians. BMJ Open 2017;7:e017856.

43 Ortashi O, Virdee J, Hassan R, et al. The practice of defensive medicine among hospital doctors in the United Kingdom. BMC Med Ethics 2013;14:42

44 Mello MM, Chandra A, Gawande AA, et al. National costs of the medical liability system. Health Aff 2010;29:1569-77.

45 NHS. The maternal and neonatal health safety collaborative, 2017. Available: https://improvement.nhs.uk/resources/maternal-andneonatal-safety-collaborative/

46 National maternity review. Better births: improving outcomes of maternity services in England. Available: https://www.england.nhs. uk/mat-transformation/implementing-better-births/mat-review/

47 Statistics OfN. Ethnic group, National identity and religion, 2010. Available: https://www.ons.gov.uk/methodology/classificationsandst andards/measuringequality/ethnicgroupnationalidentityandreligion\# ethnic-group

48 West CP, Dyrbye LN, Shanafelt TD. Physician burnout: contributors, consequences and solutions. J Intern Med 2018;283:516-29.

49 Maslach C, Jackson SE. The measurement of experienced burnout. J Organ Behav 1981;2:99-113.

50 RCOG. Training evaluation form results London. UK: Royal College of Obstetricians and Gynaecologists, 2018. https://www.rcog.org.uk/ en/careers-training/about-specialty-training-in-og/assessment-andprogression-through-training/training-evaluation-form-tef/

51 Ye J, Wang H, Wu H, et al. Burnout among obstetricians and paediatricians: a cross-sectional study from China. BMJ Open 2019;9:e024205

52 Martini S, Arfken CL, Churchill A, et al. Burnout comparison among residents in different medical specialties. Acad Psychiatry 2004;28:240-2.

53 Shanafelt TD, Boone S, Tan L, et al. Burnout and satisfaction with work-life balance among US physicians relative to the general US population. Arch Intern Med 2012;172:1377-85.

54 RCOG. O\&G Workforce Report London. UK: Royal College of Obstetricians and Gynaecologists, 2017. https://www.rcog.org.uk/ workforce 2017

55 Tawfik DS, Profit J, Morgenthaler TI, et al. Physician burnout, wellbeing, and work unit safety grades in relationship to reported medical errors. Mayo Clin Proc 2018;93:1571-80.

56 Chu C, Buchman-Schmitt JM, Stanley IH, et al. The interpersona theory of suicide: a systematic review and meta-analysis of a decade of cross-national research. Psychol Bull 2017;143:1313-45.

57 Schernhammer ES, Colditz GA. Suicide rates among physicians: a quantitative and gender assessment (meta-analysis). AJP 2004:161:2295-302. 
58 Shanafelt TD, Balch CM, Dyrbye L, et al. Special report: suicidal ideation among American surgeons. Arch Surg 2011;146:54-62.

59 Dyrbye LN, Shanafelt TD. Physician burnout: a potential threat to successful health care reform. JAMA 2011;305:2009-10.

60 Shanafelt T, Sloan J, Satele D, et al. Why do surgeons consider leaving practice? J Am Coll Surg 2011;212:421-2.

61 Panagioti M, Geraghty K, Johnson J. How to prevent burnout in cardiologists? A review of the current evidence, gaps, and future directions. Trends Cardiovasc Med 2018;28:1-7.

62 Goodman MJ, Schorling JB. A mindfulness course decreases burnout and improves well-being among healthcare providers. Int $J$ Psychiatry Med 2012;43:119-28.

63 Babbar S, Renner K, Williams K. Addressing obstetrics and gynecology trainee burnout using a Yoga-Based wellness initiative during dedicated education time. Obstet Gynecol 2019;133:994-1001.

64 Shanafelt TD, Noseworthy JH, Leadership E. Executive leadership and physician well-being: nine organizational strategies to promote engagement and reduce burnout. Mayo Clin Proc 2017;92:129-46.
65 West CP, Dyrbye LN, Erwin PJ, et al. Interventions to prevent and reduce physician burnout: a systematic review and meta-analysis. The Lancet 2016;388:2272-81.

66 Shanafelt TD, Balch CM, Bechamps GJ, et al. Burnout and career satisfaction among American surgeons. Ann Surg 2009;250:107-15.

67 Levin KH, Shanafelt TD, Keran CM, et al. Burnout, career satisfaction, and well-being among US neurology residents and fellows in 2016. Neurology 2017;89:492-501.

68 Amoafo E, Hanbali N, Patel A, et al. What are the significant factors associated with burnout in doctors?: table 1. Occup Med 2015;65:117-21.

69 Dyrbye LN, Thomas MR, Eacker A, et al. Race, ethnicity, and medical student well-being in the United States. Arch Intern Med 2007;167:2103-9.

70 Dyrbye L, Shanafelt T. A narrative review on burnout experienced by medical students and residents. Med Educ 2016;50:132-49.

71 West CP, Shanafelt TD, Kolars JC, et al. Quality of life, burnout, educational debt, and medical knowledge among internal medicine residents. JAMA 2011;306:952-60. 